\title{
Levels of active tyrosine kinase receptor determine the tumor response to Zalypsis
}

\author{
Victoria Moneo ${ }^{1}$, Beatriz G Serelde², Carmen Blanco-Aparicio ${ }^{2}$, Ramon Diaz-Uriarte ${ }^{3}$, Pablo Avilés ${ }^{1}$, \\ Gemma Santamaría', Juan C Tercero ${ }^{1}$, Carmen Cuevas $^{1}$ and Amancio Carnero ${ }^{4,5,6^{*}}$
}

\begin{abstract}
Background: Zalypsis ${ }^{\oplus}$ is a marine compound in phase II clinical trials for multiple myeloma, cervical and endometrial cancer, and Ewing's sarcoma. However, the determinants of the response to Zalypsis are not well known. The identification of biomarkers for Zalypsis activity would also contribute to broaden the spectrum of tumors by selecting those patients more likely to respond to this therapy.

Methods: Using in vitro drug sensitivity data coupled with a set of molecular data from a panel of sarcoma cell lines, we developed molecular signatures that predict sensitivity to Zalypsis. We verified these results in culture and in vivo xenograft studies.

Results: Zalypsis resistance was dependent on the expression levels of PDGFRa or constitutive phosphorylation of c-Kit, indicating that the activation of tyrosine kinase receptors (TKRs) may determine resistance to Zalypsis. To validate our observation, we measured the levels of total and active (phosphorylated) forms of the RTKs PDGFRa/ $\beta$, c-Kit, and EGFR in a new panel of diverse solid tumor cell lines and found that the IC50 to the drug correlated with RTK activation in this new panel. We further tested our predictions about Zalypsis determinants for response in vivo in xenograft models. All cells lines expressing low levels of RTK signaling were sensitive to Zalypsis in vivo, whereas all cell lines except two with high levels of RTK signaling were resistant to the drug.
\end{abstract}

Conclusions: RTK activation might provide important signals to overcome the cytotoxicity of Zalypsis and should be taken into consideration in current and future clinical trials.

Keywords: Zalypsis, Marine compound, PDGFR, Tyrosine kinase receptors, Antitumor compound

\section{Background}

During the past 30 years, medical oncologists have focused on optimizing the outcome of cancer patients by developing new antitumoral agents and defining new prognostic factors as well as integrating more effective supportive care measures. However, clinical anticancer strategies indicate that conceptually active therapies benefit only a small proportion of patients; thus, a large cohort of patients must be exposed to these antitumoral treatments to obtain a benefit in only a fraction of them.

Pharmacogenomic studies are aimed at identifying predictive biomarkers that can help to define subpopulations of patients who will, or will not, benefit from a particular

\footnotetext{
* Correspondence: acarnero-ibis@us.es

${ }^{4}$ Instituto de Biomedicina de Sevilla, IBIS/Hospital Universitario Virgen del Rocio/CSIC/Universidad de Sevilla, Sevilla, Spain

${ }^{5}$ Consejo Superior de Investigaciones Cientificas, Sevilla, Spain

Full list of author information is available at the end of the article
}

therapy. These molecular markers of a response to a specific drug are not exclusive to the so-called "Targeted Therapies" but also have been identified for widely used cytotoxic agents. Representative examples include the relationship between mRNA expression and response and survival using antifolates [1], beta tubulin III mRNA levels and response to tubulin-interacting agents [2], PTEN methylation and resistance to CPT-11 [3], and Ras oncogenic activation and resistance to EGFR-interacting agents [4].

Zalypsis $^{\circ}$ (PM00104) is a marine-derived compound that has shown cytotoxic activity against various human tumor cell lines both in vitro and in vivo, including cell lines resistant to other chemotherapeutic agents $[5,6]$. Zalypsis is a novel antineoplastic agent currently in phase II clinical development in endometrial and cervical cancer, 
multiple myeloma, and Ewing's sarcoma (http://clinicaltrials. gov/ct2/show/NCT01222767).

Structurally, Zalypsis contains a similar chemical scaffold to trabectedin, differing in an additional appended ring [7]. It has been shown that the trabectedin chemical scaffold forms a covalent bond with DNA [8], and the appended ring has been proposed to directly interact with the nucleotide excision repair (NER) endonuclease XPG $[9,10]$. Trabectedin and Zalypsis exhibit overall similarities and sequence-specific differences in their DNA footprint properties [7]. In vitro data suggests that Zalypsis has DNA-binding properties, induces cell cycle arrest, and inhibits transcription, eventually leading to apoptosis [5,11]. Although the precise mechanism of action of this agent remains mostly unknown, there is increasing experimental data describing Zalypsis' antitumoral activity $[12,13]$. The binding to the minor groove of DNA is the main event in the antitumoral activity of Zalypsis and results in stabilization of the DNA duplex [11], mimicking a inter-strand crosslink. Treatment of cells lines with Zalypsis leads to cell cycle delay in $S$ phase, activation of the DNA damage checkpoint, and cell death. Additionally, Schizosaccharomyces pombe cells containing a RAD51 mutation were found to be extremely sensitive to Zalypsis, suggesting that the compound induces double-strand breaks (DSBs) [5]. Experiments in isogenic cell lines have indicated that the cytotoxic effect of this compound is independent of functional nucleotide excision repair system properties [7]. However, the DNA damage repair machinery is essential to overcoming Zalypsis-induced DNA damage, suggesting that this damage is mainly due to DSBs [5].

The aim of this study was to identify biomarkers defining the molecular basis of sensitivity/resistance to Zalypsis to assist in its clinical development. To this end, we used a panel of solid tumors, including low-passage cell lines from untreated sarcoma tumor samples [14]. Using this panel of low-passage tumor cell lines, we assessed sensitivity to Zalypsis and other drugs currently used in sarcoma treatment [15] and found well-defined differences in sensitivity to the drugs tested. We analyzed the relationship between the IC50 to Zalypsis in the panel of tumor cell lines and the expression of a large panel of molecular markers, observing significant relationships between the direct alterations of the markers and specific compounds. The most relevant finding was that the increased signaling from RTKs determines Zalypsis resistance in vitro and in xenograft models in vivo.

\section{Methods}

\section{Cell lines and culture conditions}

The panel was composed of commercial and in-housegenerated cell lines from patients of soft tissue sarcomas. For the generation of new cell lines, sterile fragments from resected tumors were minced in culture medium and then disaggregated by $1-2 \mathrm{~h}$ incubation in collagenase $(100 \mathrm{U} / \mathrm{ml})$ at $37^{\circ} \mathrm{C}$. After $24 \mathrm{~h}$, the medium was changed to F-10 Ham (Gibco) supplemented with 1\% Ultroser G (Biosepra). The cell lines generated were cultured in F-10 Ham supplemented with 1\% Ultroser G. A673 cells were cultured in RPMI (Sigma) and SW872 in Leibovitz L-15 (Sigma). All media were supplemented with $10 \% \mathrm{FBS}$, fungizone, and penicillin/streptomycin. Once the cells became confluent, adherent cells were removed by trypsin treatment and seeded at $1 / 2$ or $1 / 3$ ratio with medium. Throughout the establishment of these cell lines, their phenotypic features were followed. Additionally, the cell lines were routinely checked for mycoplasma contamination (INVIVOGEN). All cell lines used were established immortal tumor cell lines.

For the newly created human cell lines from resected tumor tissue, approval from local ethics committee at Hospital Universitario Virgen del Rocio (Comite etico de investigacion Hospital Universitario Virgen Del Rocío) was obtained (PI2012-0085) and informed consent was obtained from patients.

\section{Cytotoxicity assessment}

The compounds were tested using 96-well trays. Cells growing in a flask were harvested just before becoming confluent, counted using a hemocytometer, and diluted with media by adjusting the concentration to the required number of cells per $0.2 \mathrm{ml}$ (volume for each well). The cells were then seeded in 96-well trays at a density between 1,000 and 4,000 cells/well, depending on the cell size. The cells were allowed to settle down and grow for 24 hours before adding the drugs, which were weighed and diluted with DMSO to a concentration of $10 \mathrm{mM}$. A "mother plate" with serial dilutions was prepared at 200X the final concentration in the culture; 11 different concentrations were tested at $1 / 3$ dilution in a range from $10 \mu \mathrm{M}$ to $0.1 \mathrm{nM}$. When necessary, for highly sensitive or highly resistant cell lines, a new mother plate was generated by decreasing or increasing two more concentrations, as required. The final concentration of DMSO in the tissue culture media did not exceed $0.5 \%$. The appropriate volume of the compound solution (usually $2 \mu \mathrm{l}$ ) was added automatically (Beckman FX 96 tip) to the media to reach the final concentration for each drug. The medium was removed from the cells and replaced with $0.2 \mathrm{ml}$ of medium dosed with drug. Each concentration was assayed in triplicate. Two sets of control wells were included in each plate, containing either medium without drug or medium with the same concentration of DMSO. A third control set was obtained with the untreated cells just before the addition of the drugs (seeding control, number of cells starting the culture). The cells were exposed to the drugs for 96 hours 
and then washed twice with phosphate-buffered saline before being fixed with $10 \%$ glutaraldehyde. The cells were washed twice, fixed with crystal violet $0.5 \%$ for 30 minutes, washed extensively, solubilized with $15 \%$ acetic acid, and absorbance measured at $595 \mathrm{~nm}$. The value of cytotoxicity was given as an IC50 concentration, the concentration a particular drug needed to inhibit by $50 \%$ the proliferation of a cell line or kill $50 \%$ of a cell population.

\section{RT-PCR}

Total RNA was collected using the TRI-REAGENT (Molecular Research Center, Inc.). RT was performed (Promega) with $1 \mu \mathrm{g}$ of RNA following the manufacturer's protocol. cDNA $(1 \mu \mathrm{g})$ was used for PCR, and the amplified products were analyzed by electrophoresis on a $1 \%$ agarose gel. The PCR primers used and the length of the amplified product are shown in Additional file 1: Table S1.

\section{Western blot analysis}

Whole-cell extracts were prepared from cells and processed as previously reported [16]. Briefly, the harvested cells were washed once in cold phosphate-buffered saline (PBS) and suspended in $1 \mathrm{ml}$ lysis-buffer (50 mM Tris- $\mathrm{HCl}$ pH 7.5, 1\% NP-40, 10\% glycerol, $150 \mathrm{mM} \mathrm{NaCl,} 2 \mathrm{mM}$, and Complete protease inhibitor cocktail -Roche-). The protein content of the lysates was determined by the modified method of Bradford. Proteins were separated on 7.5\% SDS-PAGE gels, transferred onto Immobilon-P membranes (Millipore), immunostained, and visualized using the ECL detection system (Amersham). The expression of different proteins was determined using the antibodies described in Additional file 2: Table S2.

\section{Statistical analysis}

Univariate Cox models were used to analyze the correlation between the IC50 for the drug and the expression of each biomarker in the cell line panel. For each drug, we therefore performed 15 Cox regression analyses, one for each biomarker. The p-values obtained in the Cox regression analysis were used to determine the relevance of the biomarker for predicting the sensitivity to the drug.

\section{In vivo xenograft response to Zalypsis}

The experimental research on mice performed in this work complied with institutional, national, and international guidelines for the welfare of animals and was approved by the local ethics committee (Comité Ético de Experimentación Animal(CEEA)/CEI HU Virgen Del Rocío/IBIS).

Four to six week-old athymic nu/nu mice (Harlan Sprague Dawley) were s.c. xenografted into their right flank with approx. $0.5-1 \times 10^{7}$ cells in $0.2 \mathrm{ml}$ of a mixture (50:50; v:v) of Matrigel basement membrane matrix
(Beckton Dickinson, Franklin Lakes, NJ, USA) and serumfree medium. When the tumors reached approx. $150 \mathrm{~mm}^{3}$, the mice were randomly assigned into treatment or control groups. Zalypsis ${ }^{\oplus}$ was intravenously administered either in 3 consecutive weekly doses $(0.9 \mathrm{mg} / \mathrm{kg} /$ day $)$ or in 2 cycles of 5 consecutive daily doses $(0.3 \mathrm{mg} / \mathrm{kg} /$ day $)$. Control animals received an equal volume of vehicle. Caliper measurements of the tumor diameters were performed twice weekly, and the tumor volumes were calculated according to the following formula: $(a \cdot b) 2 / 2$, where $a$ and $b$ were the longest and shortest diameters, respectively. The animals were humanely euthanized, according to Institutional Animal Care and Use Committee of PharmaMar, Inc. (Cambridge, MA, USA) guidelines, when their tumors reached $3000 \mathrm{~mm}^{3}$ or if significant toxicity (e.g., severe body weight reduction) was observed. Differences in tumor volumes between the treated and control groups were evaluated using the unpaired t-test. Statistical significance was defined as $\mathrm{p}<0.05$. The statistical analyses were performed by LabCat v8.0 SP1 (Innovative Programming Associates, Inc. NJ, USA).

\section{Results}

Analysis of expression of biomarkers in the cell line panel The expression of protein and mRNA levels from different genes were analyzed under basal conditions in the absence of the drug and correlated with the in vitro sensitivity after exposure to Zalypsis, trabectedin, and doxorubicin. The panel included 22 genes involved in tumor progression, cell adhesion, cell cycle control, and cell signaling: Apaf-1, APC, cdk4, c-Kit, cyclin D1, E-cadherin, MDM2, MLH-1, MSH-2, p14 ${ }^{\mathrm{ARF}}, \mathrm{p} 15^{\mathrm{INK} 4 \mathrm{~b}}, \mathrm{p} 16^{\mathrm{INK} 4 \mathrm{a}}$, p $21^{\text {cip } 1}, \mathrm{p} 27^{\mathrm{kip} 1}, \mathrm{p} 53, \mathrm{p} 73, \mathrm{p} 85$, PDGFR $\alpha, \mathrm{p} 60^{\mathrm{src}}, \mathrm{PTEN}$, $\mathrm{pAKT}$, and $\beta$-catenin. Fourteen genes were analyzed by the presence or absence of mRNA, and the remaining genes were evaluated by the protein level (see Additional file 1: Table S1, Additional file 2: Table S2 and Additional file 3: Table S3 for indication). For the statistical analysis, the presence or absence of RNA of each biomarker in each cell line was scored as 1 or 0 , respectively (see Additional file 3: Table S3). For proteins, intermediate values were included when some biological relevance had been described for different levels. Only 15 biomarkers showed differences among the different cell lines and were used for the statistical analyses.

\section{Sensitivity to Zalypsis, trabectedin, and doxorubicin of low-passaged sarcoma cell lines}

The panel of low-passage human sarcoma cell lines was treated with different concentrations of Zalypsis, trabectedin, and doxorubicin. The values of sensitivity (IC50) to trabectedin and doxorubicin were determined for comparison. The $\mathrm{IC}_{50}$ values were calculated as an average of three independent experiments performed in 
triplicate (Table 1). Response to each drug varied largely between the most sensitive and most resistant cell lines. In fact, the median IC50 for doxorubicin was $232 \mathrm{nM}$ (range 14 to $>300$ ), indicating at least a 20-fold difference in sensitivity in the cell lines from the studied panel. The cell line panel was highly sensitive to trabectedin, with a median IC50 of $0.7 \mathrm{nM}$ (range 0.1 to $>100,1000$-fold difference). According to a previous report [14], the value of $1 \mathrm{nM}$ IC50 is considered as the cut-off to separate cell lines sensitive or resistant to trabectedin (Table 1).

Similarly, the cell line panel showed a broad range of responses to Zalypsis, with a median IC50 of $502 \mathrm{nM}$ (range 0.16 to 4933). It is evident that the panel cell lines can be divided into two groups according to sensitivity to Zalypsis, sensitive lines with an IC50 below $1 \mathrm{nM}$ and resistant lines with an IC50 above $100 \mathrm{nM}$, establishing a more than 100-fold difference between the sensitive and resistant groups. Although liposarcoma-derived cell lines are highly sensitive to trabectedin and Zalypsis, there is no tissue pattern for the response, and the sensitivity to Zalypsis did not correlate with that for trabectedin (Table 1). Both trabectedin and Zalypsis showed a

Table 1 IC50 \pm SD values (nM) of a panel of low-passaged sarcoma cell lines in response to trabectedin, Zalypsis, and doxorubicin

\begin{tabular}{|c|c|c|c|c|}
\hline Cell line & Tumor origin & $\begin{array}{l}\text { Doxo } \\
\text { (nM) }\end{array}$ & $\begin{array}{l}\text { Trabectedin } \\
\text { (nM) }\end{array}$ & $\begin{array}{c}\text { Zalypsis } \\
\text { (nM) }\end{array}$ \\
\hline CNIO AW & LIPOSARCOMA & 45 & $0.7 \pm 0.1$ & $0.16 \pm 0.02$ \\
\hline CNIO AX & LIPOSARCOMA & 44 & $0.7 \pm 0.3$ & $0.32 \pm 0.15$ \\
\hline SW872 & LIPOSARCOMA & $>300$ & $0.5 \pm 0.1$ & $0.87 \pm 0.53$ \\
\hline 1455 & LIPOSARCOMA & $>300$ & $0.1 \pm 0.02$ & $0.34 \pm 0.32$ \\
\hline CNIO AA & LEYOMYOSARCOMA & 21.5 & $0.4 \pm 0.1$ & $0.5 \pm 0.13$ \\
\hline CNIO AY & LEYOMYOSARCOMA & 44 & $9 \pm 0.3$ & $2580 \pm 1785$ \\
\hline CNIO AZ & FIBROUS TUMOR & 14 & $5 \pm 0.3$ & $870 \pm 184.5$ \\
\hline CNIO BC & MPNST & $>300$ & $>100$ & $664.75 \pm 450.5$ \\
\hline CNIO BB & MPNST & 232 & $>100$ & $1008.35 \pm 353$ \\
\hline A673 & EWING SARCOMA & 50 & $1 \pm 0.07$ & $0.42 \pm 0.39$ \\
\hline CNIO BJ & OSTEOSARCOMA & $>300$ & $2 \pm 0.32$ & $103.2 \pm 4.38$ \\
\hline CNIO BF & OSTEOSARCOMA & 15 & $0.3 \pm 0.04$ & $501.95 \pm 9.83$ \\
\hline CNIO BP & OSTEOSARCOMA & $>300$ & $0.3 \pm 0.05$ & $0.29 \pm 0.10$ \\
\hline SAOS-2 & OSTEOSARCOMA & $>300$ & $0.11 \pm 0.02$ & $0.94 \pm 0.74$ \\
\hline CNIO BG & MIXOID FIBROSARC & 22 & $0.3 \pm 0.02$ & $1200 \pm 565.69$ \\
\hline CNIO BM & HIBERNOMA & $>300$ & $10 \pm 0.9$ & $3473 \pm 169.71$ \\
\hline CNIO BN & FIBROHISTIOCITOMA & $>300$ & $>100$ & $4750 \pm 70.71$ \\
\hline CNIO CE & RABDOMIOSARC & $>300$ & $>100$ & $2401 \pm 637.81$ \\
\hline CNIO BI & GIST & 50 & $0.1 \pm 0.02$ & $4933 \pm 644.88$ \\
\hline
\end{tabular}

The data represent the average IC50 \pm SD of three experiments performed independently. In the case of doxorubicin, only the average IC50 is shown. MPNST: Malignant peripheral nerve sheath tumor. GIST: Gastrointestinal stromal tumor. pattern of sensitivity that was different from doxorubicin, which suggests no cross-resistance.

To explore trabectedin and Zalypsis sensitivity further, we analyzed the relevance of each of the molecular markers for trabectedin and Zalypsis responses. To this end, we performed univariate Cox regression analyses to determine the relationship between sensitivity to Zalypsis $\left(\mathrm{IC}_{50}\right)$ and the expression pattern of each marker across the cell line panel. Therefore, we performed 15 Cox regression analyses, one for each marker. We then compared the relevance of each molecular marker to the sensitivity to trabectedin or Zalypsis and compared with another 12 drugs previously analyzed [17]. The multiple comparisons were expressed as a sensitivity homology tree view (Figure 1), which represents the similarity in the relevance of 15 different molecular markers with regard to drug responses. According to the 15 markers analyzed, trabectedin and Zalypsis behave differently because they fall into different sensitivity homology tree branches. We can also observe that, although Zalypsis behaves similarly to oxaliplatin, trabectedin is closer to rapamycin or gemcitabine (Figure 1). Our sensitivity homology tree does not group the drugs by mechanism of action but by the relevance of certain markers to predict sensitivity or resistance, which clearly can be independent of the mechanism of action of each drug. Furthermore, Zalypsis and trabectedin also showed a different marker homology than doxorubicin, confirming the lack of cross-resistance in vitro and in patients previously described and indicating that

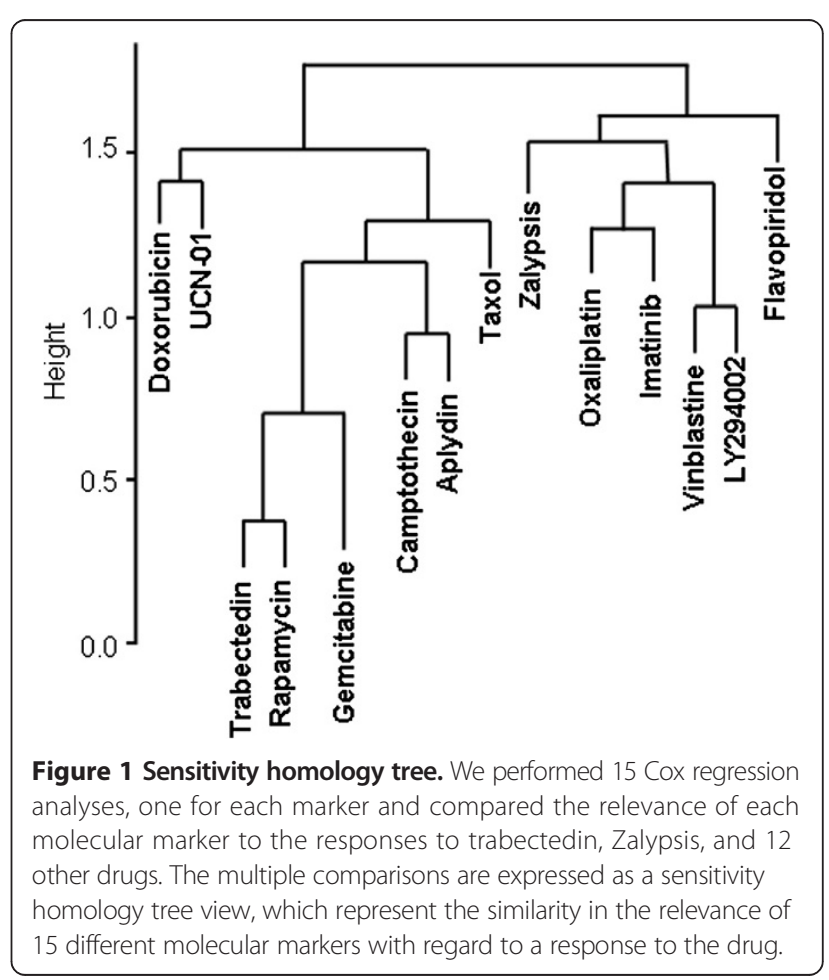


they might be complementary to doxorubicin in treating solid tumors, especially sarcoma.

\section{Statistical analysis of biomarker expression correlation with sensitivity to Zalypsis}

Next, we used the 15 independent univariate Cox regression analyses to determine the relationship between sensitivity to trabectedin or Zalypsis $\left(\mathrm{IC}_{50}\right)$ and the expression pattern of each biomarker. As expected due to previous work [14], the p53 status was the main determinant of a trabectedin response in our cell line panel. However, we also found as secondary determinants PDGFR $\alpha$ and Cyclin D1, with statistically relevant predictive values.

We also found that the correlation of high PDGFR $\alpha$ expression and resistance to Zalypsis was the only relationship showing a statistically relevant value $(\mathrm{p}<0.05)$
(Figure 2A and $\mathrm{B}$ ). Cell lines with higher a IC50 for Zalypsis (AZ, BC, AY, BB, BM, BN, BG, and CE) showed higher levels of PDGFR $\alpha$. Furthermore, BF (from osteosarcoma) and BI (from GIST), also resistant to Zalypsis, showed low PDGFR $\alpha$ levels but high levels of c-Kit (Figure 2C). A multivariate Cox regression analysis was also performed to explore the possibility of combining several markers to obtain a better predictive signature. In fact, the combined presence of high levels of c-Kit increased the statistical significance of the correlation (Figure 2B). None of the cells exhibited increased levels of EGFR (data not shown). We confirmed the cellular data for Zalypsis by comparing the cellular levels of PDGFR $\alpha$ and c-Kit with the IC50 for Zalypsis in each cell line (Figure $2 \mathrm{C}$ ). These data suggest that the activation of either tyrosine kinase receptor could induce resistance to Zalypsis.

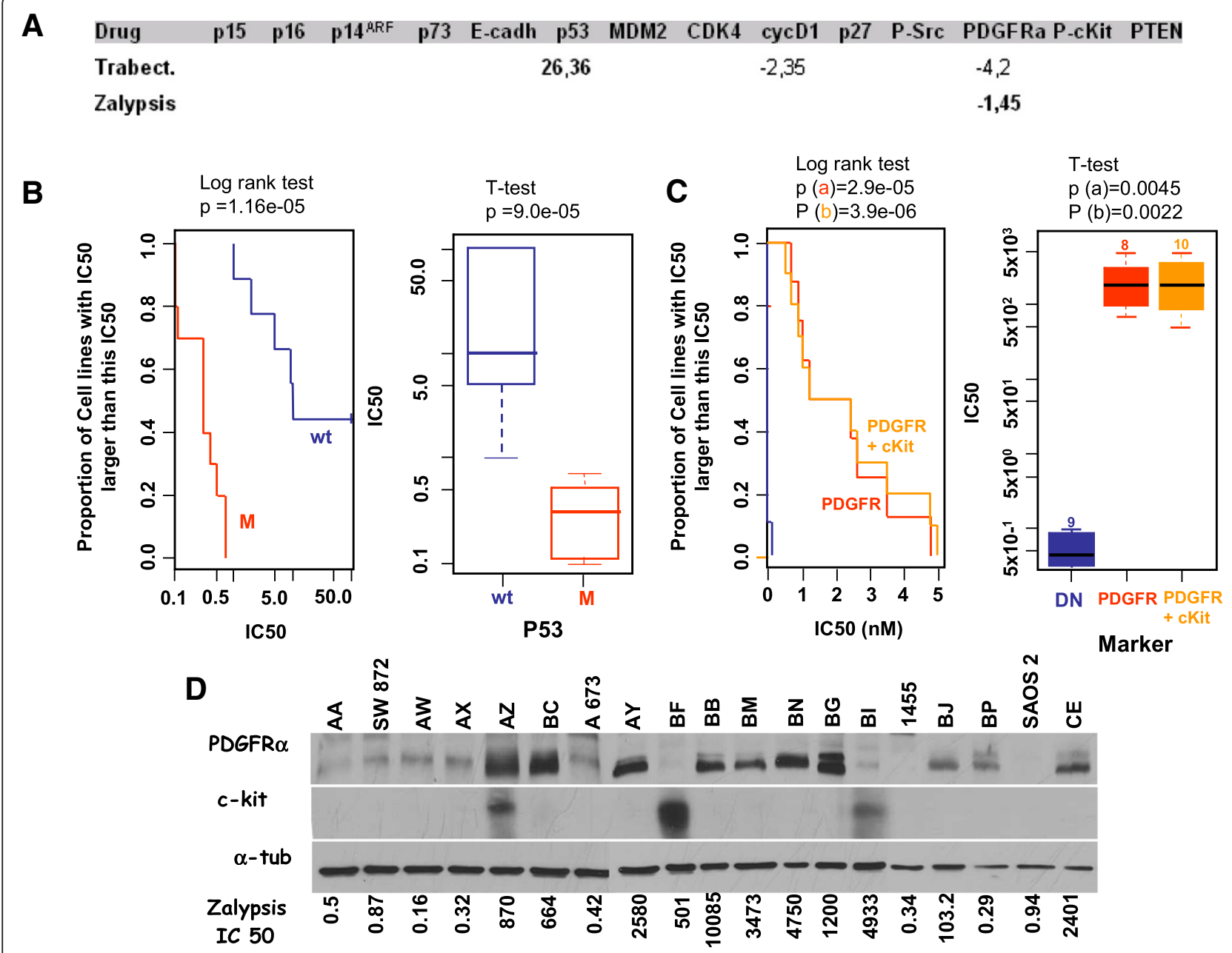

Figure 2 Correlation of markers with trabectedin and Zalypsis cytotoxicity. A) Statistically relevant $(p<0.005)$ correlations of molecular markers with trabectedin or Zalypsis treatment. The number indicates the correlation coefficient between the marker and the drug. B and C) Statistical graphs showing the correlation between individual markers and responses in the log rank test or Student t-test. The $p$ value shows the statistical relevance of these correlations. B) Correlation of p53 mutations and the trabectedin IC50 (nM). M: mutant p53; WT: wild-type p53. C) Correlation of PDGFR/PDGFR + c-Kit and the Zalypsis IC50. D) Expression of PDGFRa and c-Kit proteins across the cell line panel and correlation with sensitivity (IC50 values) to Zalypsis. 


\section{Validation of the response to receptor tyrosine kinase activation}

Our aim was to identify a predictive biomarker that allows the use of Zalypsis in a personalized manner and, if possible, to broaden the spectrum of tumors that can be treated with this drug. To validate the signature obtained in the sarcoma cell lines, we selected 9 new cell lines of other solid tumor origin, which, different from the lowpassaged sarcoma cell lines, can also grow as xenografts and therefore can also be used for in vivo validation.

The 9 cell lines were subjected to analysis to determine the levels of RTKs. To this end, we broadened the proteins analyzed and examined PDGFR $\alpha$, PDGFR $\beta$, EGFR, and c-Kit activation (measured as receptor phosphorylation) and the total levels at $10 \%$ or $0.5 \%$ serum (Figure 3). We found constitutive activation of the PDGFR signal, either $\alpha$ or $\beta$, in the A2780, Calu6, HGC27, and SW1990 cell lines and also in MDA-MB-231 cells. Furthermore, EGFR was constitutively activated in SKOV3 cells. None of the 9 cell lines showed c-Kit activation (data not shown). The IC50 for Zalypsis in the cell lines showed a rank from $13 \mathrm{nM}$ to $0.6 \mathrm{nM}$, with SW1990, Calu6, and SKOV3 cells presenting an IC50 above the average. Figure 4A shows a comparison of the IC50 for Zalypsis with the constitutive activation of RTKs. Figure 4B shows a comparison of the IC50 of the cell lines with activated RTKs vs non-activated RTKs, with a borderline statistical significance $(p=0.069)$. As in the sarcoma cell line panel, the cell lines with constitutive RTK activation generally showed a higher IC50 for Zalypsis in vitro (Figure 4). However, the correlation did not occur in all cell lines because MDA-MB-231 cells had a low IC50, indicating that other factors may contribute to Zalypsis sensitivity in this cell line.

\section{In vivo response to Zalypsis in xenograft models}

In vitro studies indicated that high levels of RTK phosphorylation and activation determined resistance to Zalypsis treatment. With the aim of validating this marker in vivo, we generated xenografts from the 9 cell lines that can be xenografted in mice. We used these cells because the low-passage sarcoma cells used in the predictive panel do not grow exponentially when xenografted in immunosuppressed mice. The xenografts of the different cell lines were treated with Zalypsis either at $0.3 \mathrm{mg} /$ $\mathrm{kg} /$ day, qdx5x2. or $0.9 \mathrm{mg} / \mathrm{kg} /$ day, qdx7x3. A positive response was considered a reduction higher than $60 \%$ of the tumor burden with respect to the control, untreated tumor.

Of the 9 cell line xenografts tested, 5 responded to treatment with Zalypsis, and 4 did not respond. The non-responding xenografts comprised CALU6, HGC27, SW1990, and SKOV-3 cells (Figure 5), all of which, except SKOV-3, showed high levels of phosphorylated PDGFR $\alpha / \beta$ (Figure 3A) under high $(10 \%)$ or low $(0.5 \%)$ serum conditions, indicating the constitutive expression

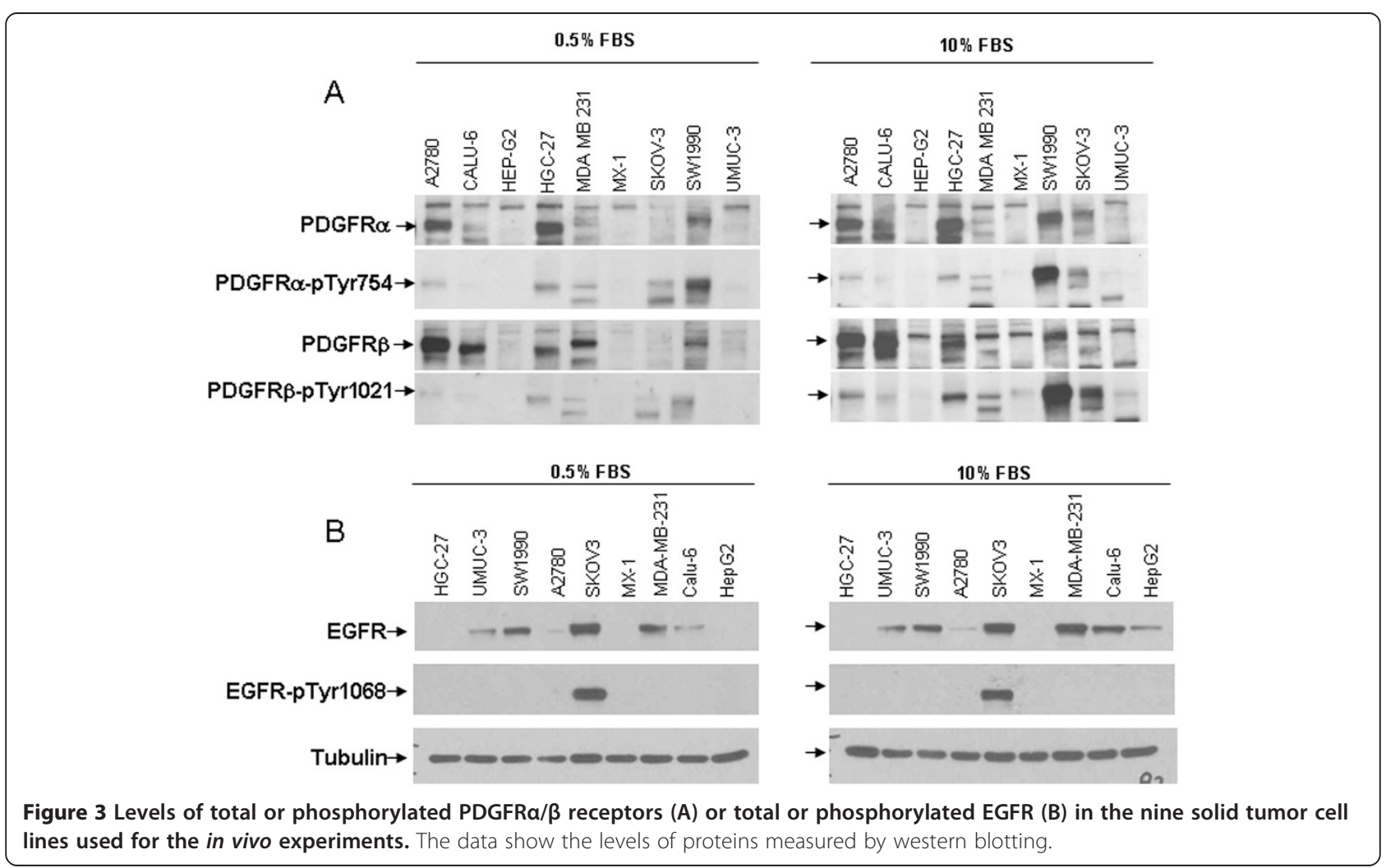




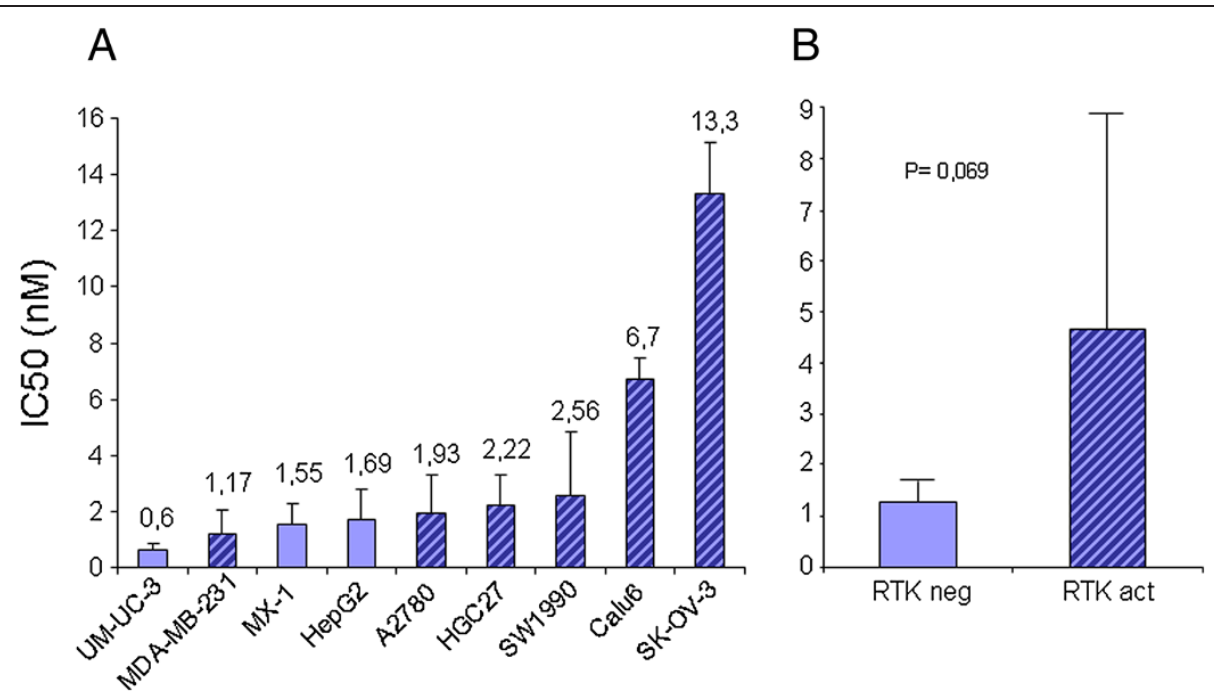

Figure 4 Correlation of Zalipsis IC50 with RTK activation. A) Graph showing the mean IC50 values for Zalypsis with respect to the average values for all IC50s. The bold bars indicate no constitutive activation of RTKs. The hatched bars indicate the activation of RTKs. The number above the bars shows the average IC50 values (nM) for the nine tumor cell lines. B) Graph comparing in groups the IC50 of cell lines with RTK activated or not activated. The Student T test was used to explore the statistical relevance.

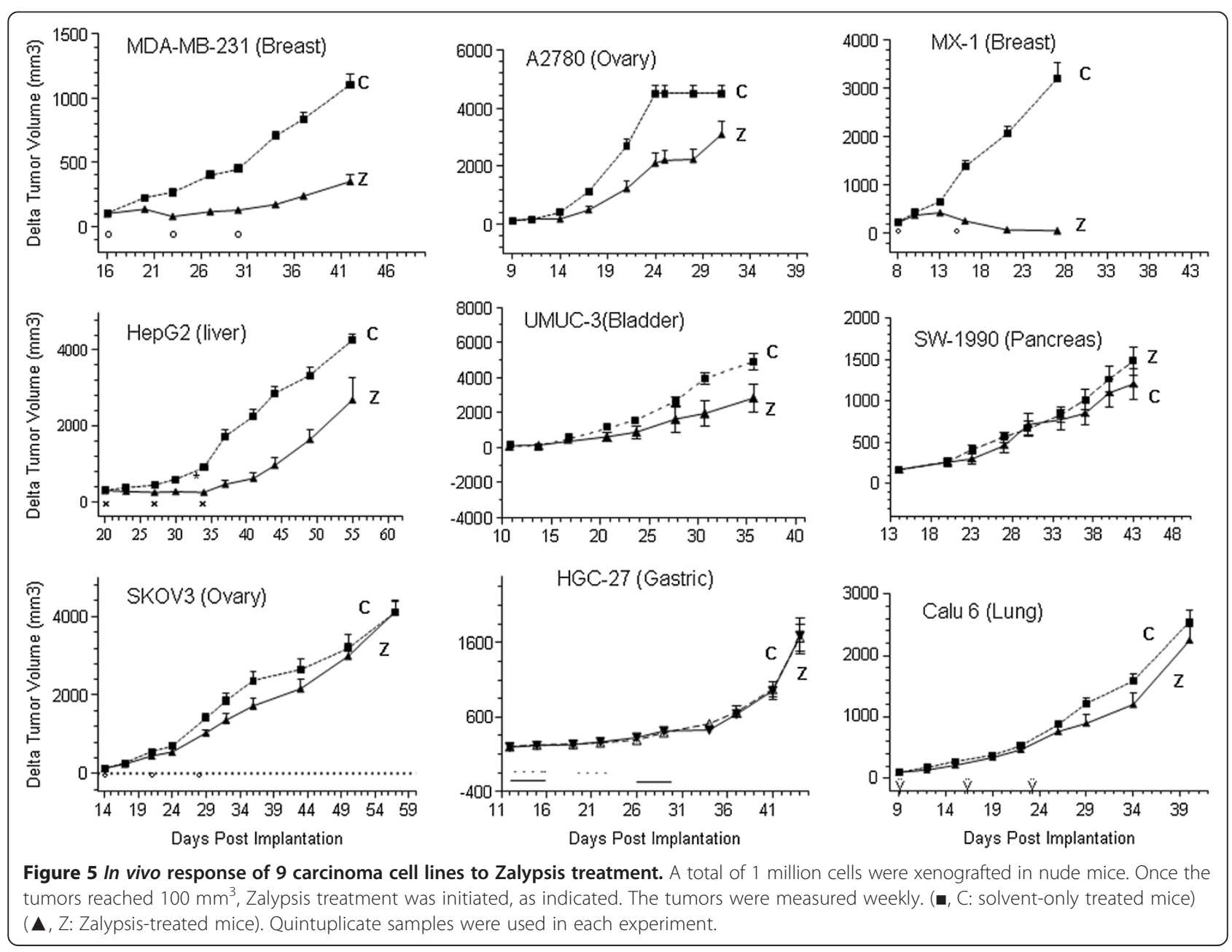


of the receptor. Furthermore, SKOV-3 was the only cell line expressing high levels phosphorylated-EGFR, indicating a constitutively active EGF receptor (Figure 3B). A2780 and MDA-MB-231 cells, with increased levels of PDGFR $\alpha / \beta$, still responded to Zalypsis treatment. The reason for this specific behavior for these cell lines is presently unclear and deserves further attention.

\section{Discussion}

Compelling evidence from a number of laboratories has demonstrated the value of using biomarkers to select individual patients for targeted and non-targeted therapies $[18,19]$. The goal is to predict a response to chemotherapy to use agents in those patients more likely to respond, avoiding unnecessary toxicity. However, in most cases, the predictors are based on molecular signatures with low functional value per se. We developed a molecular signature based on the selection of molecular markers with functional relevance. The signatures obtained not only allow for a prediction of a response but also suggest possible mechanisms to overcoming resistance.

Zalypsis showed a different sensitivity profile from trabectedin in the cell line panel studied, indicating that alternative activities in cellular pathways or specific trends of intracellular metabolism might determine different activities. However, both marine compounds show effective results in liposarcoma- and fibrohistocytoma-derived cell lines, two types of cells very resistant to treatment including doxorubicin. In the remaining cases, the activity appears to be more dependent on the cell line than the tissue type. It is possible that one of the activities of these compounds is dependent on specific factors present in some sarcoma types. These specific factors may be the specific translocations that define certain sarcoma types; alternatively, the cell lineage-dependent genetic content may establish the sensitivity or resistance to a specific drug activity.

Furthermore, we also found that combinations of PDGFR $\alpha / \beta$ with other membrane receptors, such as EGFR or c-Kit, increase the predictability of the response to Zalypsis both in vivo and in vitro. RTK constitutive signaling might trigger the constitutive activation of the survival pathway through MEK or AKT activation, therefore accounting for the combined effect observed in our cell line panel both in vivo and in vitro. Active RTKs activate PI3K, leading to PDK1 and AKT activation [20]. Activated AKT can phosphorylate the pro-apoptotic Bcl-2 family member Bax at S184, inhibiting its conformational change and its subsequent translocation to mitochondria, thus preventing Bif- 1 binding to Bax and alterations in mitochondrial membrane potential, cytochrome c release, caspase activation, and apoptosis [21-24]. Furthermore, Bcl-XL levels can be regulated by the PI3K pathway; upregulation of this protein implies survival, whereas downregulation leads to apoptosis. AKT also phosphorylates Foxo3a, inducing its mislocalization out of the nucleus and therefore inhibiting its proapoptotic activity [25]. Similarly, the phosphorylation of MDM2 by AKT induces its binding to $\mathrm{p} 53$ and the initiation of degradation, also acting on cellular survival [26]. However, RTK also activates the Ras pathway, leading to MEK and ERK activation, which also phosphorylates Bax to trigger a similar antiapoptotic response [27]. Additionally, as in the PI3K/ AKT pathway, the Ras pathway can regulate the apoptotic response through IKK phosphorylation and the regulation of NFKB signaling [28].

RTK activation has been commonly linked to the resistance to anticancer therapies, either cytotoxic or targeted. Clearly, the upregulation of another receptor or its ligand, such as MET or HGF in lung cancer resistant to EGFR inhibitors, is a matter of concern in acquired resistance to RTK-targeted therapies [29-31]. Furthermore, TKR activation also has an important role in overcoming cytotoxicity to chemotherapy in different tumor types. For example, insulin-like growth factor-I receptor activation blocks doxorubicin cytotoxicity in sarcoma cells [32], and the EGFR inhibitor gefitinib sensitizes colon cancer cells to irinotecan [33]. Cisplatin-resistant neuroblastoma cells express enhanced levels of epidermal growth factor receptor (EGFR) and are sensitive to treatment with EGFR-specific inhibitors [34]. Other receptors such as TrkB protect neuroblastoma cells from chemotherapyinduced apoptosis via the phosphatidylinositol 3'-kinase pathway [35]. RTK inhibition is also effective in chemosensitizing human ovarian, nasopharyngeal, bladder, and neuroblastoma cancer cell lines, among others, when used in combination with cytotoxic agents [36-39]. Recently, we have also reported that SNPs in the PDGFR $\beta$ gene are related to increased levels of receptor and signaling, promoting chemotherapy resistance in colorectal cancer patients [40].

The logical conclusion is that the combination of Zalypsis with tyrosine kinase inhibitors would lead to a greater efficacy of treatment. Because the constitutive activation of c-Kit might also contribute to resistance, Zalypsis + imatinib may also be an interesting combination. There are several tyrosine kinase inhibitors approved with different specificities for different tyrosine kinases [41]. Imatinib and sunitinib also inhibit PDGFR $\alpha$ and c-Kit and other RTKs, such as VEGFR1 and FLT3, whereas sorafenib appears to be more specific for PDGFR $\beta$ but also inhibits c-Kit, FLT3, and VEGFR2. Nilotinib inhibits PDGFR $\alpha$ and $-\beta$ and c-Kit. In contrast, gefitinib, erlotinib, and lapatinib are more specific for the EGFR family. We propose the use of a specific tyrosine kinase inhibitor according to the RTK active in the patient's tumor, thus promoting personalized treatment.

However, further studies have to be conducted to fully validate this approach. 


\section{Conclusions}

We identified a molecular signature based on the combined activation of tyrosine kinase receptors that predicts resistance to Zalypsis in a broad panel of solid tumor cell lines. This signature was validated in vivo in xenograft assays. This signature deserves validation in tumor samples of patients treated with Zalypsis, with clinical trials currently ongoing, and also suggests a potential benefit for the combination of Zalypsis with tyrosine kinase inhibitors, which warrants further studies.

\section{Additional files}

Additional file 1: Table S1. Primers used to identify the mRNA expression of the different molecular markers used in this study.

Additional file 2: Table S2. Antibodies used to identify the protein expression of the different molecular markers used in this study.

Additional file 3: Table S3. Results of the presence (+) or absence (-) of different mRNAs in our cell line panel. The numbers identify the relative levels of the protein in each case.

\section{Competing interests}

VM, PA, GS, JCT, and CC are Pharmamar employees.

$A C, B G S, C B-A$, and RD-U declare no competing interests.

The sponsors had no role in the study design, in the collection, analysis, and interpretation of data, or in the writing of the manuscript and the decision to submit the manuscript for publication.

\section{Authors' contributions}

VM, PA, GS, BGS, and CB-A performed the experiments. RD-U performed the statistical analysis. CB-A, JCT, CC, and AC designed the experiments and analyzed the data. AC wrote the manuscript. CB-A, JCT, CC, and AC edited the manuscript. All authors read and approved the final manuscript.

\section{Acknowledgments}

The AC lab was supported by grants to from the Spanish Ministry of Economy and Competitivity, ISCIII (Fis: PI12/00137, RTICC: RD12/0036/0028), Consejeria de Ciencia e Innovacion (CTS-6844), and Consejeria de Salud of the Junta de Andalucia (PI-0135-2010 and PI-0306-2012). We acknowledge support of the publication fee by the CSIC Open Access Publication Support Initiative through its Unit of Information Resources for Research (URICI).

\section{Author details \\ ${ }^{1}$ PharmaMar R \& D, Madrid, Spain. ${ }^{2}$ Experimental Therapeutics Programme, Spanish National Cancer Center (CNIO), Madrid, Spain. ${ }^{3}$ Structural Biology and Biocomputing Programme, Spanish National Cancer Center (CNIO), Madrid, Spain. ${ }^{4}$ Instituto de Biomedicina de Sevilla, IBIS/Hospital Universitario Virgen del Rocio/CSIC/Universidad de Sevilla, Sevilla, Spain. ${ }^{5}$ Consejo Superior de Investigaciones Cientificas, Sevilla, Spain. ${ }^{6}$ Instituto de Biomedicina de Sevilla, Hospital Universitario Virgen del Rocio, Edificio IBIS, Consejo Superior de Investigaciones Cientificas, Avda. Manuel Siurot s/n., Sevilla 41013, Spain.}

Received: 9 September 2013 Accepted: 8 April 2014

Published: 23 April 2014

\section{References}

1. Popat S, Matakidou A, Houlston RS: Thymidylate synthase expression and prognosis in colorectal cancer: a systematic review and meta-analysis. J Clin Oncol 2004, 22(3):529-536.

2. Seve P, Mackey J, Isaac S, Tredan O, Souquet PJ, Perol M, Lai R, Voloch A Dumontet C: Class III beta-tubulin expression in tumor cells predicts response and outcome in patients with non-small cell lung cancer receiving paclitaxel. Mol Cancer Ther 2005, 4(12):2001-2007.

3. Longley DB, Johnston PG: Molecular mechanisms of drug resistance. J Pathol 2005, 205(2):275-292.
4. Linardou H, Dahabreh IJ, Kanaloupiti D, Siannis F, Bafaloukos D, Kosmidis P, Papadimitriou CA, Murray S: Assessment of somatic k-RAS mutations as a mechanism associated with resistance to EGFR-targeted agents: a systematic review and meta-analysis of studies in advanced non-smallcell lung cancer and metastatic colorectal cancer. Lancet Oncol 2008, 9(10):962-972

5. Leal JF, Garcia-Hernandez V, Moneo V, Domingo A, Bueren-Calabuig JA, Negri A, Gago F, Guillen-Navarro MJ, Aviles P, Cuevas C, García-Fernández $L F$, Galmarini CM: Molecular pharmacology and antitumor activity of Zalypsis in several human cancer cell lines. Biochem Pharmacol 2009, 78(2):162-170.

6. Colado E, Paino T, Maiso P, Ocio EM, Chen X, Alvarez-Fernandez S, Gutierrez NC, Martin-Sanchez J, Flores-Montero J, San Segundo L, Garayoa M, Fernández-Lázaro D, Vidriales MB, Galmarini CM, Avilés P, Cuevas C, Pandiella A, San-Miguel JF: Zalypsis has in vitro activity in acute myeloid blasts and leukemic progenitor cells through the induction of a DNA damage response. Haematologica 2011 96(5):687-695.

7. Guirouilh-Barbat J, Antony S, Pommier Y: Zalypsis (PM00104) is a potent inducer of gamma-H2AX foci and reveals the importance of the $\mathrm{C}$ ring of trabectedin for transcription-coupled repair inhibition. Mol Cancer Ther 2009, 8(7):2007-2014.

8. Pommier Y, Kohlhagen G, Bailly C, Waring M, Mazumder A, Kohn KW: DNA sequence- and structure-selective alkylation of guanine N2 in the DNA minor groove by ecteinascidin 743 , a potent antitumor compound from the Caribbean tunicate Ecteinascidia turbinata. Biochemistry 1996, 35(41):13303-13309.

9. Herrero AB, Martin-Castellanos C, Marco E, Gago F, Moreno S: Cross-talk between nucleotide excision and homologous recombination DNA repair pathways in the mechanism of action of antitumor trabectedin. Cancer Res 2006, 66(16):8155-8162.

10. Takebayashi Y, Pourquier P, Zimonjic DB, Nakayama K, Emmert S, Ueda $\mathrm{T}$, Urasaki Y, Kanzaki A, Akiyama SI, Popescu N, Kraemer KH, Pommier Y: Antiproliferative activity of ecteinascidin 743 is dependent upon transcription-coupled nucleotide-excision repair. Nat Med 2001 7(8):961-966.

11. Erba E, Cavallaro E, Damia G, Mantovani R, Di Silvio A, Di Francesco AM, Riccardi R, Cuevas C, Faircloth GT, D'Incalci M: The unique biological features of the marine product Yondelis (ET-743, trabectedin) are shared by its analog ET-637, which lacks the C ring. Oncol Res 2004, 14(11-12):579-587.

12. Duan Z, Choy E, Jimeno JM, Cuevas Cdel M, Mankin HJ, Hornicek FJ: Diverse cross-resistance phenotype to ET-743 and PM00104 in multi-drug resistant cell lines. Cancer Chemother Pharmacol 2009, 63(6):1121-1129.

13. Ocio EM, Maiso P, Chen X, Garayoa M, Alvarez-Fernandez S, San-Segundo L, Vilanova D, Lopez-Corral L, Montero JC, Hernandez-Iglesias T, de Alava E, Galmarini C, Avilés P, Cuevas C, San-Miguel JF, Pandiella A: Zalypsis: a novel marine-derived compound with potent antimyeloma activity that reveals high sensitivity of malignant plasma cells to DNA double-strand breaks. Blood 2009, 113(16):3781-3791.

14. Moneo V, Serelde BG, Fominaya J, Leal JF, Blanco-Aparicio C, Romero L, Sanchez-Beato M, Cigudosa JC, Tercero JC, Piris MA, Jimeno J, Carnero A Extreme sensitivity to Yondelis (Trabectedin, ET-743) in low passaged sarcoma cell lines correlates with mutated p53. J Cell Biochem 2007, 100(2):339-348.

15. Chou AJ, Geller DS, Gorlick R: Therapy for osteosarcoma: where do we go from here? Paediatr Drugs 2008, 10(5):315-327.

16. Leal JF, Fominaya J, Cascon A, Guijarro MV, Blanco-Aparicio C, Lleonart M, Castro ME, Ramon YCS, Robledo M, Beach DH, Carnero A: Cellular senescence bypass screen identifies new putative tumor suppressor genes. Oncogene 2008, 27(14):1961-1970

17. Moneo V, Serelde BG, Leal JF, Blanco-Aparicio C, Diaz-Uriarte R, Aracil M, Tercero JC, Jimeno J, Carnero A: Levels of p27(kip1) determine Aplidin sensitivity. Mol Cancer Ther 2007, 6(4):1310-1316.

18. Master SR: Getting the details right: gene signatures for cancer therapy. Clin Chem 2010, 56(9):1378-1380.

19. Bild AH, Yao G, Chang JT, Wang Q, Potti A, Chasse D, Joshi MB, Harpole D, Lancaster JM, Berchuck A, Olson JA Jr, Marks JR, Dressman HK, West M, Nevins JR: Oncogenic pathway signatures in human cancers as a guide to targeted therapies. Nature 2006, 439(7074):353-357.

20. Carnero A, Blanco-Aparicio C, Renner O, Link W, Leal JF: The PTEN/PI3K/AKT signalling pathway in cancer, therapeutic implications. Curr Cancer Drug Targets 2008, 8(3):187-198. 
21. Blanco-Aparicio C, Pequeno B, Moneo V, Romero L, Leal JF, Velasco J, Fominaya J, Carnero A: Inhibition of phosphatidylinositol-3-kinase synergizes with gemcitabine in low-passage tumor cell lines correlating with Bax translocation to the mitochondria. Anticancer Drugs 2005, 16(9):977-987.

22. Gardai SJ, Hildeman DA, Frankel SK, Whitlock BB, Frasch SC, Borregaard N, Marrack P, Bratton DL, Henson PM: Phosphorylation of Bax Ser184 by Akt regulates its activity and apoptosis in neutrophils. J Biol Chem 2004, 279(20):21085-21095.

23. Yamaguchi $H$, Wang HG: The protein kinase PKB/Akt regulates cell survival and apoptosis by inhibiting Bax conformational change. Oncogene 2001, 20(53):7779-7786.

24. Link W, Rosado A, Fominaya J, Thomas JE, Carnero A: Membrane localization of all class I PI 3-kinase isoforms suppresses c-Myc-induced apoptosis in Rat1 fibroblasts via Akt. J Cell Biochem 2005, 95(5):979-989.

25. Zanella F, Link W, Carnero A: Understanding FOXO, new views on old transcription factors. Curr Cancer Drug Targets 2010, 10(2):135-146.

26. Gottlieb TM, Leal JF, Seger R, Taya Y, Oren M: Cross-talk between Akt, p53 and Mdm2: possible implications for the regulation of apoptosis. Oncogene 2002, 21(8):1299-1303.

27. Cox AD, Der CJ: The dark side of Ras: regulation of apoptosis. Oncogene 2003, 22(56):8999-9006.

28. Mayo MW, Norris $J$, Baldwin AS: Ras regulation of NF-kappa B and apoptosis. Methods Enzymol 2001, 333:73-87.

29. Jones HE, Gee JM, Hutcheson IR, Knowlden JM, Barrow D, Nicholson RI: Growth factor receptor interplay and resistance in cancer. Endocr Relat Cancer 2006, 13(Suppl 1):S45-S51.

30. Hopper-Borge EA, Nasto RE, Ratushny V, Weiner LM, Golemis EA, Astsaturov I: Mechanisms of tumor resistance to EGFR-targeted therapies. Expert Opin Ther Targets 2009, 13(3):339-362.

31. Hrustanovic G, Lee BJ, Bivona TG: Mechanisms of resistance to EGFR targeted therapies. Cancer Biol Ther 2013, 14(4):304-314.

32. Beech DJ, Perer E, Helms J, Gratzer A, Deng N: Insulin-like growth factor-I receptor activation blocks doxorubicin cytotoxicity in sarcoma cells. Oncol Rep 2003, 10(1):181-184.

33. Braun AH, Stark K, Dirsch O, Hilger RA, Seeber S, Vanhoefer U: The epidermal growth factor receptor tyrosine kinase inhibitor gefitinib sensitizes colon cancer cells to irinotecan. Anticancer Drugs 2005, 16(10):1099-1108.

34. Michaelis M, Bliss J, Arnold SC, Hinsch N, Rothweiler F, Deubzer HE, Witt O, Langer K, Doerr HW, Wels WS, Cinatl J Jr: Cisplatin-resistant neuroblastoma cells express enhanced levels of epidermal growth factor receptor (EGFR) and are sensitive to treatment with EGFR-specific toxins. Clin Cancer Res 2008, 14(20):6531-6537.

35. Jaboin J, Kim CJ, Kaplan DR, Thiele CJ: Brain-derived neurotrophic factor activation of TrkB protects neuroblastoma cells from chemotherapyinduced apoptosis via phosphatidylinositol 3'-kinase pathway. Cancer Res 2002, 62(22):6756-6763.

36. Coley HM, Shotton CF, Ajose-Adeogun A, Modjtahedi H, Thomas H: Receptor tyrosine kinase (RTK) inhibition is effective in chemosensitising EGFRexpressing drug resistant human ovarian cancer cell lines when used in combination with cytotoxic agents. Biochem Pharmacol 2006, 72(8):941-948.

37. Hsu CH, Gao M, Chen CL, Yeh PY, Cheng AL: Inhibitors of epidermoid growth factor receptor suppress cell growth and enhance chemosensitivity of nasopharyngeal cancer cells in vitro. Oncology 2005, 68(4-6):538-547.

38. Mattingly RR, Milstein ML, Mirkin BL: Down-regulation of growth factorstimulated MAP kinase signaling in cytotoxic drug-resistant human neuroblastoma cells. Cell Signal 2001, 13(7):499-505.

39. Takeuchi A, Eto M, Shiota M, Tatsugami K, Yokomizo A, Kuroiwa K, Itsumi M, Naito S: Sunitinib enhances antitumor effects against chemotherapyresistant bladder cancer through suppression of ERK1/2 phosphorylation. Int J Oncol 2012, 40(5):1691-1696.
40. Estevez-Garcia P, Castano A, Martin AC, Lopez-Rios F, Iglesias J, MunozGalvan S, Lopez-Calderero I, Molina-Pinelo S, Pastor MD, Carnero A, Paz-Ares L, Garcia-Carbonero R: PDGFRalpha/beta and VEGFR2 polymorphisms in colorectal cancer: incidence and implications in clinical outcome. BMC Cancer 2012, 12:514

41. van Erp NP, Gelderblom H, Guchelaar HJ: Clinical pharmacokinetics of tyrosine kinase inhibitors. Cancer Treat Rev 2009, 35(8):692-706.

doi:10.1186/1471-2407-14-281

Cite this article as: Moneo et al:: Levels of active tyrosine kinase receptor determine the tumor response to Zalypsis. BMC Cancer 2014 14:281.

\section{Submit your next manuscript to BioMed Central and take full advantage of:}

- Convenient online submission

- Thorough peer review

- No space constraints or color figure charges

- Immediate publication on acceptance

- Inclusion in PubMed, CAS, Scopus and Google Scholar

- Research which is freely available for redistribution

Submit your manuscript at www.biomedcentral.com/submit
C BioMed Central 